Article

\title{
Reward-Penalty Mechanism Based on Daily Energy Consumption for Net-Zero Energy Buildings
}

\author{
Yang Zhang, Yuehong Lu *, Changlong Wang, Zhijia Huang and Tao Lv
}

check for updates

Citation: Zhang, Y.; Lu, Y.; Wang, C.; Huang, Z.; Lv, T. Reward-Penalty Mechanism Based on Daily Energy Consumption for Net-Zero Energy Buildings. Sustainability 2021, 13, 12838. https://doi.org/10.3390/ su132212838

Academic Editor: Anna Visvizi

Received: 26 October 2021

Accepted: 14 November 2021

Published: 19 November 2021

Publisher's Note: MDPI stays neutral with regard to jurisdictional claims in published maps and institutional affiliations.

Copyright: (c) 2021 by the authors. Licensee MDPI, Basel, Switzerland. This article is an open access article distributed under the terms and conditions of the Creative Commons Attribution (CC BY) license (https:// creativecommons.org/licenses/by/ $4.0 /)$.
Department of Civil Engineering and Architecture, Anhui University of Technology, Ma'anshan 243002, China; zhya-8214@163.com (Y.Z.); clwang2017@163.com (C.W.); hzj@ahut.edu.cn (Z.H.); lvtao456@163.com (T.L.)

* Correspondence: luyuehongtuzi@163.com

\begin{abstract}
Net-zero energy buildings (ZEB/NZEB) have been greatly encouraged and are considered to be a promising approach for energy conservation as well as environmental protection. However, a lack of incentive mechanisms can hinder the fast development and application of ZEB. This study thus focuses on the design of a daily reward-penalty mechanism (RPM) by considering the performance of the building, aiming to enable a lower penalty cost for the building where there is a better match between energy consumption and energy generation. The impact of the degree of freedom of the building load $(\mathrm{k})$ is investigated on building performance based on a single-family house located in Shanghai city, China. It is observed that a higher value of $\mathrm{k}$ is preferred since the building users can adjust its energy consumption profile to better match with its energy generation. A higher $\mathrm{k}$ value enables lower annual energy consumption, lower penalty cost, better stability, and an average daily zero energy level of around 1.0. In addition, four quadratic fit curves are derived to describe the relationship between building performance (i.e., annual energy consumption, the average daily zero energy level, stability, and annual penalty cost) and the degree of freedom. Meanwhile, the uncertainty of ZEB performance is quantified, which provides flexibility for building users in selecting the appropriate degree of freedom.
\end{abstract}

Keywords: net-zero energy building; reward-penalty mechanism; uncertainty analysis; degree of freedom; stability

\section{Introduction}

Policies and governance on energy resources are vital and feasible strategies in the face of energy shortage and environmental pollution. A sequence of policies that are designed from local to global enables a systemic transition towards more efficient energy regimes [1]. There are three major strategies that are proposed for sustainable energy development: energy saving by passive design [2,3], the improvement of energy efficiency in energy systems [4,5], and the application of renewable energy systems [6,7].

A reward-penalty mechanism/scheme is a good approach that has been applied in different fields, but especially by electricity distribution companies, to ensure an adequate level of reliability to customers by rewarding (or penalizing) the distribution system operator when the target is fulfilled (or not fulfilled) [8,9]. Reward-penalty schemes can be employed in various forms in electric distribution networks by regulators to ensure services reliability. The uncertainty of services' reliability causes financial risk faced by distribution system operators. Therefore, the projects of reliability reinforcement can be applied to reinforce the service reliability, which should be managed in a way that a higher profit can be received at lower risk [10]. A decision-making model is presented to update the parameters of the reward and penalty scheme in each regulatory period and to improve the efficiency of this scheme, based on which, an objective function is formulated as a non-linear programming problem to optimize investment cost, imposed cost, and the amounts of reward and penalty for the distribution company [11]. The incentive-based demand response programs may lead to a peak rebound and congestion in the distribution 
system, endangering a reliable and sustainable electricity supply to urban consumers. A reward-penalty demand response program for customers is proposed in the study [12], where the customers may be rewarded as they shift their demands within requested hours and may also receive a penalty if their demands exceed predefined thresholds. In another study [13], the function of reward and penalty is formulated by considering both manufacturers and utility companies, in which the aim is to mitigate the overgeneration from the uncontrollable property of renewable sources.

The wide application of feed-in-tariff (FIT) has paved the way for achieving ZEB since it plays a crucial role in the development of renewable energy technologies in the building sector. As of 2019, FIT policies have been implemented in 113 jurisdictions [14]. For instance, Hitaj and Löschel [15] estimated the impact of FIT in installed wind power capacity in Germany. Ye et al. [16] investigated the tariff levels of the FIT for solar PV power in China and concluded that the tariff levels should be adjusted more frequently to keep the internal rate of return. Schmidt et al. [17] analyzed the effects of the fixed-price FIT and the premium-based FIT in a policy experiment for Austria. Gornowicz et al. [18] investigated a grid-connected rooftop PV system in Poland aiming to identify the optimal system configuration for two support mechanisms (i.e., the scenario of net-metering and FIT). Pacudan [19] assessed policy options for the proposed 5-year rooftop solar PV deployment program in Brunei Darussalam. Tantisattayakul [20] conducted a feasibility analysis of grid-connected solar PV rooftops for households based on the present FIT framework. It demonstrated that it is not sufficient to promote investment in PV rooftops in the residential sector under the current FIT based on the current market situation.

Although substantial literature has been focused on definitions and metrics for ZEB [21,22], optimization methodologies for energy system size [23-25] and power management strategy [26-28], only a few studies have been conducted on financial incentive schemes for a specific building, i.e., ZEB. In our previous study [29], a segment function was proposed to be the model of penalty cost in the design of zero energy buildings, in which the parameters were determined by trial tests, but it was difficult to obtain them in different cases. Therefore, a simple quadratic function was further proposed as the reward-penalty model for the design of zero energy buildings, based on which a ZEB owner can receive a bonus at 1.0ZEB design, while the building owners would be fined according to the achieved ZEB level [30]. However, it was still difficult to ensure a good performance for the building even if it was designed as a ZEB as large fluctuations of energy flow between the building and the grid can also cause serious problems. In order to better match the energy generation and energy consumption in the designed ZEB, a reward-penalty function is proposed by considering daily energy consumption and energy stability in the building. Since building users usually have the freedom to change their energy consumption profile, the degree of freedom on the building load is defined as the flexibility of building load in this study, based on which, the impact of different degrees of the freedom on the building performance can be identified for ZEB and non-ZEB. Therefore, the degree of freedom is an indicator to quantify the range of variation in building load according to building energy generation. In addition, the relationship between building performance (i.e., annual energy consumption, the average daily zero energy level, stability, and annual penalty cost) and degree of freedom is worth formulating to provide guidance on selecting a suitable degree of freedom. Following on from this introduction, the structure for the remainder of this paper is as follows: The methodology on the design of daily reward-penalty function is presented in Section 2. A single-family house located in Shanghai, China is selected to be the test building, as described in Section 3. The proposed method is then tested in the building in terms of daily performance and annual performance, and uncertainty analysis is conducted to further provide building users information on the performance of ZEB under different selections and degree of freedom, as presented in Section 4. Conclusions are provided in Section 5. 


\section{Methodology}

For ZEBs, the annual energy consumption in the building can be satisfied by energy generation from on-site renewable energy (RES), as shown in Equation (1), where, $E_{g e n, i}$ represents daily energy generation and $E_{c o n, i}$ represents daily energy consumption. However, an annual balanced ZEB may cause great stress on the grid due to its unbalance between energy generation and energy consumption based on a daily evaluation. That is to say, ZEBs with lower power fluctuation are expected to be better than those with higher power fluctuation. As shown in Figure 1, ZEBs labeled as 'a' had a much higher fluctuation than those labeled as ' $b$ '. Profile ' $b$ ' is preferred since it causes less stress on the grid and thus it has a higher independence. The daily level of zero energy buildings $\left(R_{z e b, i}\right)$ can be described as the ratio between daily energy generation $\left(E_{g e n, i}\right)$ and daily energy consumption $\left(E_{c o n, i}\right)$, as shown in Equation (2). It is noted that the expression of $\beta Z E B$ is defined based on annual evaluation in this study, where $\beta Z \mathrm{ZEB}$ can be 0.0ZEB, 0.2ZEB, 0.4ZEB, 0.6ZEB, 0.8ZEB, and 1.0ZEB. 0.0ZEB means there is no generation in this building, while 1.0ZEB means the amount of annual energy generation equals to the amount of annual energy consumption in this building. Stability $(\sigma)$ can be used to describe the annual performance of power fluctuation, as shown in Equation (3), where, a smaller value of stability indicates a better match between energy generation and energy consumption, thus a better performance of ZEB is derived.

$$
\begin{gathered}
\sum_{i=1}^{365} E_{c o n, i} \leq \sum_{i=1}^{365} E_{g e n, i} \\
R_{z e b, i}=\frac{E_{g e n, i}}{E_{c o n, i}} \\
\sigma=\sqrt{\sum_{i=1}^{365}\left(R_{z e b, i}-1.0\right)^{2} / 365}
\end{gathered}
$$

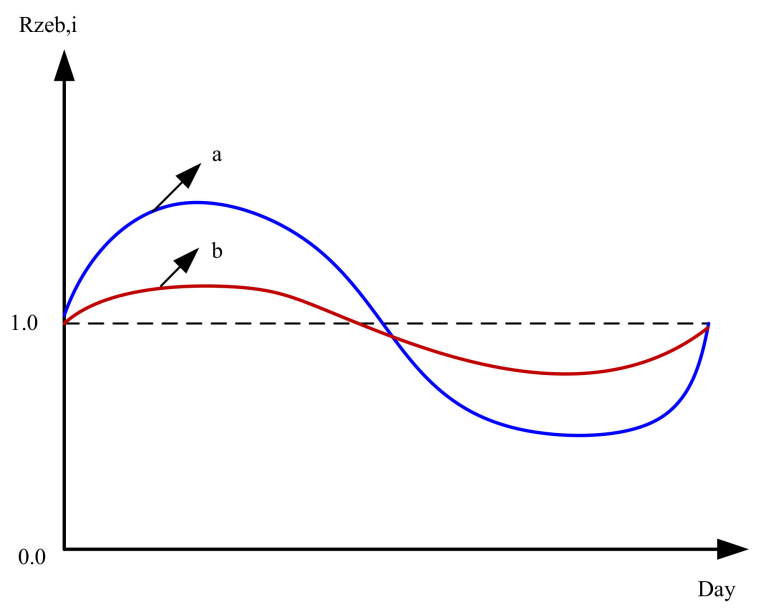

Figure 1. Two basic profiles on power fluctuation in ZEBs.

In order to realize the high performance of a building, a daily reward-penalty mechanism can be designed by considering the price of power from the grid $\left(C_{\text {grid }}\right)$, the daily energy consumption, and power fluctuation, as shown in Equation (4), where, $C_{p e}$ and $C_{p e, i}$ represent the annual reward-penalty cost and the daily reward-penalty cost. In this study, $\alpha$ is a coefficient that represents the degree of impact of the three parameters $\left(C_{\text {grid }}, E_{c o n, i}\right.$, $R_{z e b, i}$ ) on the reward-penalty cost, and it is selected as 2.0. The building that consumes higher energy is expected to have a higher penalty cost, while a lower level of ZEB and greater power fluctuation are also served with higher penalty cost.

$$
C_{p e}=\sum_{i=1}^{365} C_{p e, i}=\alpha \times C_{\text {grid }} \times \sum_{i=1}^{365} E_{c o n, i} \times\left(R_{z e b, i}-1.0\right)^{2}
$$


Based on the reward-penalty mechanism (Equation (4)), building users can adjust the pattern of daily building load to achieve less penalty cost. An indicator, the degree of freedom $(\mathrm{k})$, can be used to express the flexibility of the load in the building. As described in the following flow chart, when the building energy consumption is larger than energy generation, building users can reduce its energy consumption. Then, further compare the reduced energy consumption based on the degree of freedom (i.e., $\left.E_{c o n, i *(1-k)}\right)$ with the energy generation, and the final building energy consumption equals to the larger one. By contrast, when the building energy consumption is smaller than energy generation, building users can increase their energy consumption. Then, further compare the increased energy consumption based on the degree of freedom (i.e., $E_{c o n, i}{ }^{*}(1+k)$ ) with the energy generation, and the final building energy consumption equals to the smaller one. A diagram showing the relationship between the degree of freedom, energy generation, and energy consumption is provided in Figure 2.

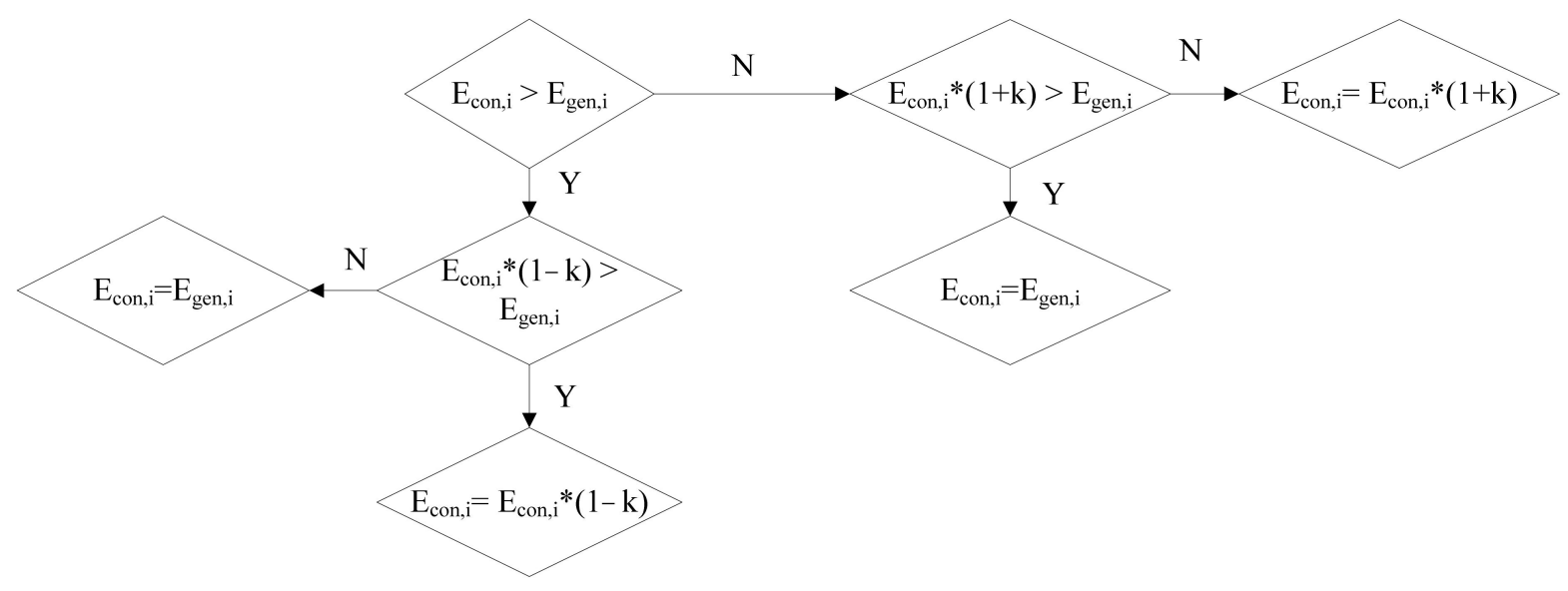

Figure 2. Relationship among the degree of freedom, energy generation, and energy consumption.

To identify the effectiveness of the proposed daily reward-penalty function for different buildings, Monte Carlo simulations are used to generate the hourly building energy consumption (BEC). In this study, the generated energy consumption of a building per hour $\mathrm{j}\left(E_{c o n, j}^{\prime}\right)$ is assumed to follow a normal distribution where the standard deviation is arbitrarily taken to be 0.5 time of the mean value, which can be expressed as shown in Equation (5) [30]. $\varepsilon$ is the ratio of the newly generated energy consumption of a building in hour $\mathrm{j}$ to that of the standard building, and it is selected to $0.2,0.6,1.4$, and 1.8 .

$$
E_{c o n, j}^{\prime} \sim \varepsilon \times N\left(E_{c o n, j},\left(0.5 \times E_{c o n, j}\right)^{2}\right)
$$

\section{Case Study}

A single-family house located in Shanghai city, China was developed to evaluate the performance of the proposed reward-penalty function. The house has an area of $100 \mathrm{~m}^{2}$, and the basic appliances, including a television set, computer, lighting, washing machine, and water heater, etc. The energy usage for each appliance was set based on the parameters from reference [23], as shown in Table 1. The power for each appliance was set as: lighting $(30 \mathrm{~W} \times 6)$, television set $(150 \mathrm{~W})$, computer $(70 \mathrm{~W})$, washing machine $(300 \mathrm{~W})$, water heater $(3500 \mathrm{~W})$, electric cooker $(800 \mathrm{~W})$, and small power appliances $(100 \mathrm{~W})$. Based on the habits of local people under the concept of energy conversation, the air conditioner wasswitched on to provide heating when the outdoor temperature was below $10^{\circ} \mathrm{C}$ during winter time and to provide cooling when the outdoor temperature was above $30^{\circ} \mathrm{C}$ during summer. Generally, the electricity consumption of this house was around $19.1 \mathrm{kWh}$ per day. To realize the target of annual energy balance between energy consumption and energy generation, PV panel was assumed to be the on-site energy generation system. The 
efficiency of PV panel was $18 \%$ at standard test conditions, and its lifetime was 25 years. The electricity price in Shanghai applied step tariff for residential buildings. In our study, we use the average price as electricity price $(0.1 \mathrm{USD} / \mathrm{kWh})$ for the single-family house in Shanghai.

Table 1. Energy usage of household appliances in a single-family house [30].

\begin{tabular}{cccc}
\hline Appliance & $\begin{array}{c}\text { Power } \\
\text { (W) }\end{array}$ & $\begin{array}{c}\text { Average Use Time } \\
\text { (h/day) }\end{array}$ & $\begin{array}{c}\text { Electricity Used } \\
\text { (kWh/day) }\end{array}$ \\
\hline Lighting & $30 \mathrm{~W} \times 6$ & 6 & 1.08 \\
Television set & 150 & 5 & 0.75 \\
Computer & 70 & 3 & 0.21 \\
Washing machine & 300 & 1 & 0.30 \\
Water heater & 3500 & 1 & 3.5 \\
Electric cooker & 800 & 1.5 & 1.20 \\
Small power appliances & 100 & Summer: Tout $>30{ }^{\circ} \mathrm{C}, \mathrm{AC}$ is & 2.40 \\
Air conditioner (AC) & Winter: Tout < $10{ }^{\circ} \mathrm{C}, \mathrm{AC}$ is on & 9.70 \\
Total electricity consumption & & \\
\hline
\end{tabular}

Solar radiation was the key parameter that affected energy generation in the building, and outdoor temperature was the key parameter that affected the building energy consumption. As shown in Figures 3 and 4, the daily solar radiation in each month ranges from $1.99 \mathrm{kWh}$ to $5.10 \mathrm{kWh}$, and the average daily solar radiation is $3.626 \mathrm{kWh}$. Since PV array is designed to provide electricity for the building, the PV energy generation can be calculated by Equation (6), where $E_{p v, j}$ is the PV generation per $\mathrm{kW}$ at the hour $\mathrm{j}, \mathrm{f}_{\mathrm{pv}}$ is the PV derating factor (\%) and is selected to be $0.9, I_{T, j}$ is the solar radiation (beam plus diffuse) incident on the surface of the PV array $\left(\mathrm{kW} / \mathrm{m}^{2}\right)$ at the time $\mathrm{j}$, and $\mathrm{I}_{\mathrm{S}}$ is the incident radiation under standard test conditions $\left(1 \mathrm{~kW} / \mathrm{m}^{2}\right)$. The temperature coefficient of power is represented by $\mathrm{kp}\left(\% /{ }^{\circ} \mathrm{C}\right), T_{\mathrm{C}}$ and $T_{\mathrm{STC}}$ are the $\mathrm{PV}$ module temperatures in the current hour $\left({ }^{\circ} \mathrm{C}\right)$ and under standard test conditions $\left(25^{\circ} \mathrm{C}\right)$. The PV efficiency was set as $18 \%$ in the standard test condition. Therefore, $\mathrm{E}_{\mathrm{pv}, \mathrm{j}}$ represents daily PV generation and is equal to $E_{g e n, i}$ in Equation (2), and $E_{p v}$ represents the annual PV generation and equals to $E_{g e n}$ in this study. It is noted that we assumed the photovoltaic array was installed at optimum inclination angle.

$$
E_{p v, j}=f_{p v} \frac{I_{T, j}}{I_{\mathrm{S}}}\left[1+k_{\mathrm{p}}\left(T_{\mathrm{C}, \mathrm{j}}-T_{\mathrm{STC}}\right)\right]
$$

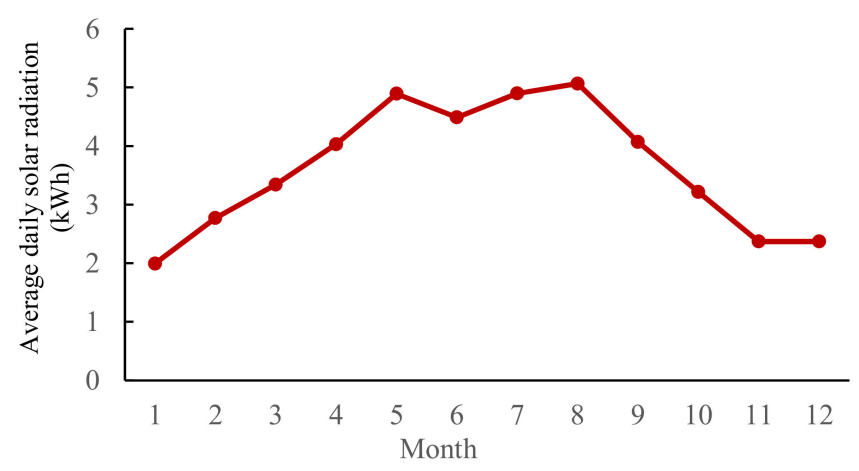

Figure 3. The average daily solar radiation in each month in Shanghai city. 


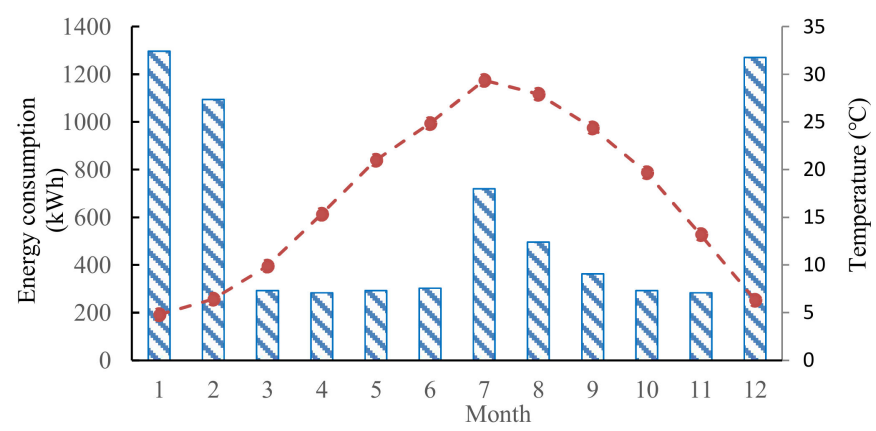

Figure 4. Average monthly ambient temperature and energy consumption of the house.

The ambient temperature in each month ranged from 4.8 to $29.4{ }^{\circ} \mathrm{C}$, and the average ambient temperature was $16.9^{\circ} \mathrm{C}$. Meanwhile, the building energy consumption in each month ranged from $283.2 \mathrm{kWh}$ to $1296.7 \mathrm{kWh}$, and the annual energy consumption was approximately $6983.9 \mathrm{kWh}$ for this single-family house.

\section{Results and Analysis}

\subsection{Daily Performance of ZEB Based on RPM}

In order to achieve the net-zero energy target for the house, PV panels of $5.41 \mathrm{~m}^{2}$ was selected to be installed in the building. Six values of the degree of freedom $(\mathrm{k})$ were selected for the building, i.e., $\mathrm{k}=0.0,0.2, \ldots, 1.0$. Figure 5 shows the distribution of daily zero energy levels for the building under different degrees of freedom. The maximum value of the daily zero energy level of the building was observed to reduce from 4.04 to 2.02 , and the minimum value of the daily zero energy level of the building was observed to increase from 0.04 to 1.0 when $\mathrm{k}$ was increased from 0.0 to 1.0. Meanwhile, the average daily zero energy level of the building was reduced from 1.51 to 1.14 , which caused a great reduction in the stability value $(\sigma)$ from 1.20 to 0.29 . It was also found that when $\mathrm{k}$ equaled 1.0, most of the daily zero energy levels were around 1.0. Therefore, a building with a higher value of $\mathrm{k}$ is preferred since building users have better flexibility in adjusting its energy consumption profile to match its energy generation.

Figure 6 further displayed the daily zero energy level and the corresponding penalty cost for the building over 21 days (i.e., from day 181 to 201). It can be observed that when $\mathrm{k}$ equaled 0.0 , the daily zero energy level of the building fluctuated greatly, i.e., from 0.51 to 1.88. This caused a large fluctuation in its penalty cost, from $0.0 \mathrm{USD} /$ day to $2.3 \mathrm{USD} /$ day. With the increase of $k$ value, the daily zero energy level of the building was observed to be much more stable, especially when k equaled 0.8 and 1.0, the daily zero energy level of the building was around 1.0. Meanwhile, the penalty cost was also kept stable at 0.0 when $\mathrm{k}$ equaled 0.8 and 1.0. Therefore, the daily zero energy level was an important factor in determining the value of the penalty cost in the building. 

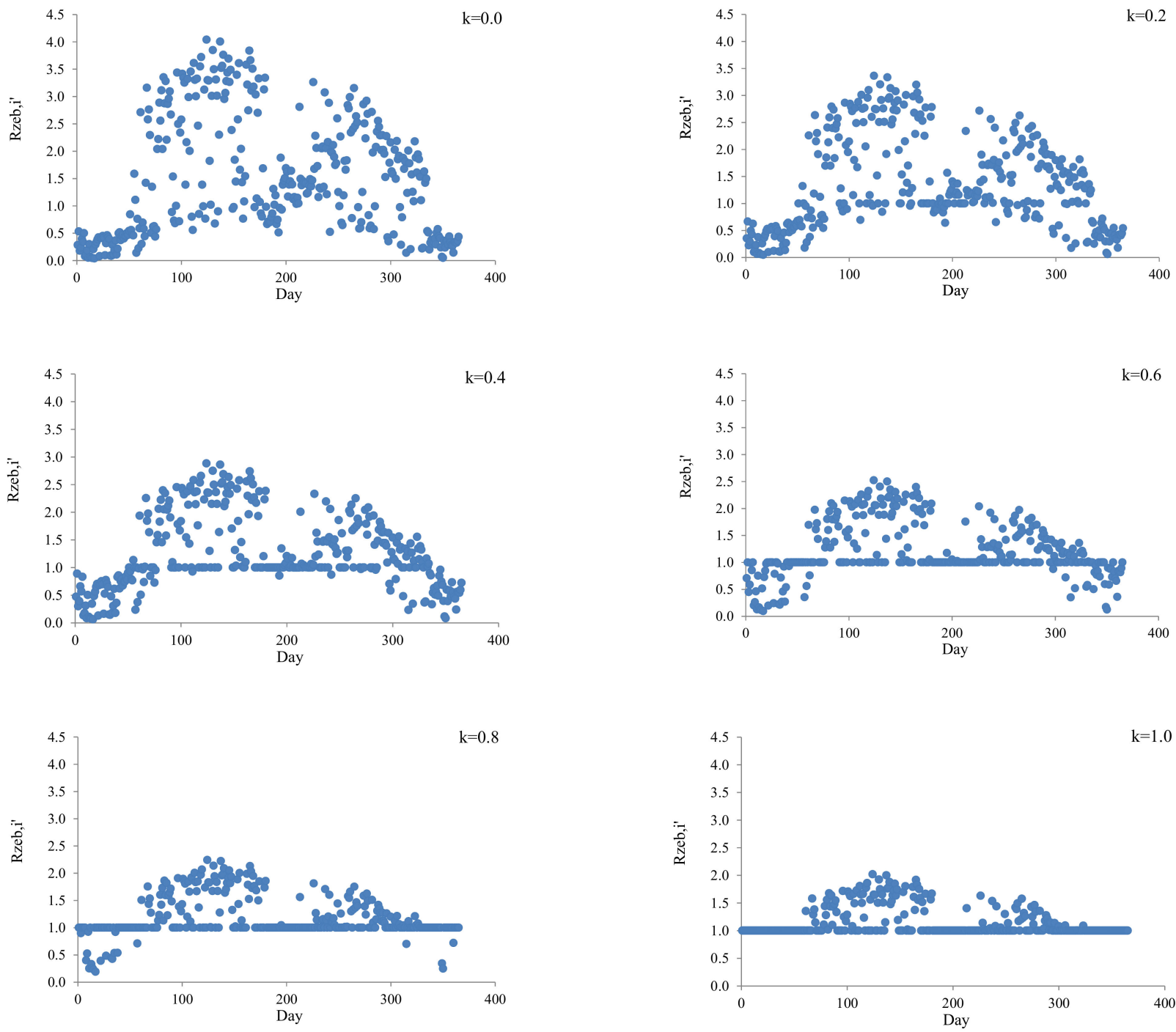

Figure 5. Distribution of daily zero energy level for the building in 365 days. 

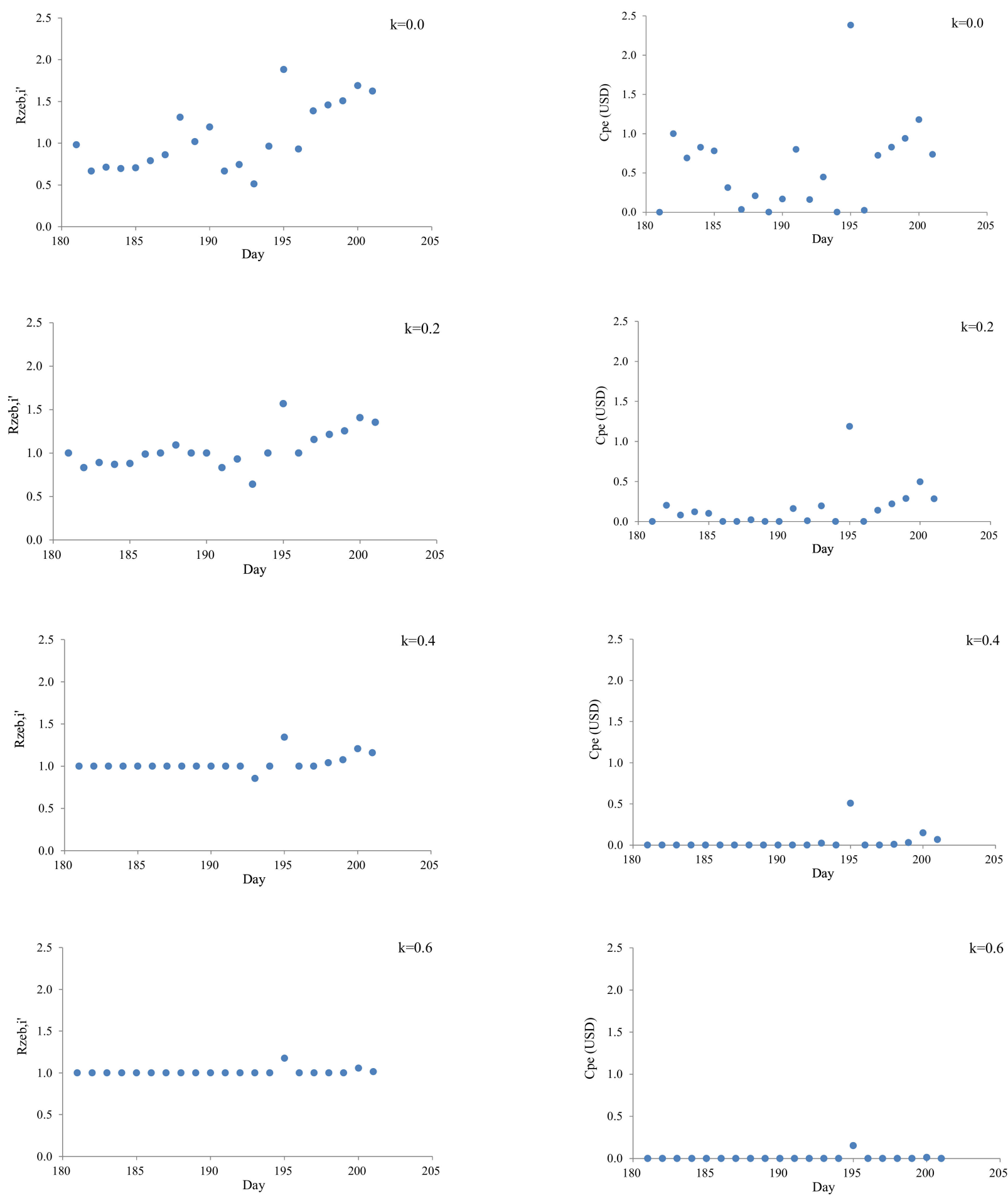

Figure 6. Cont. 

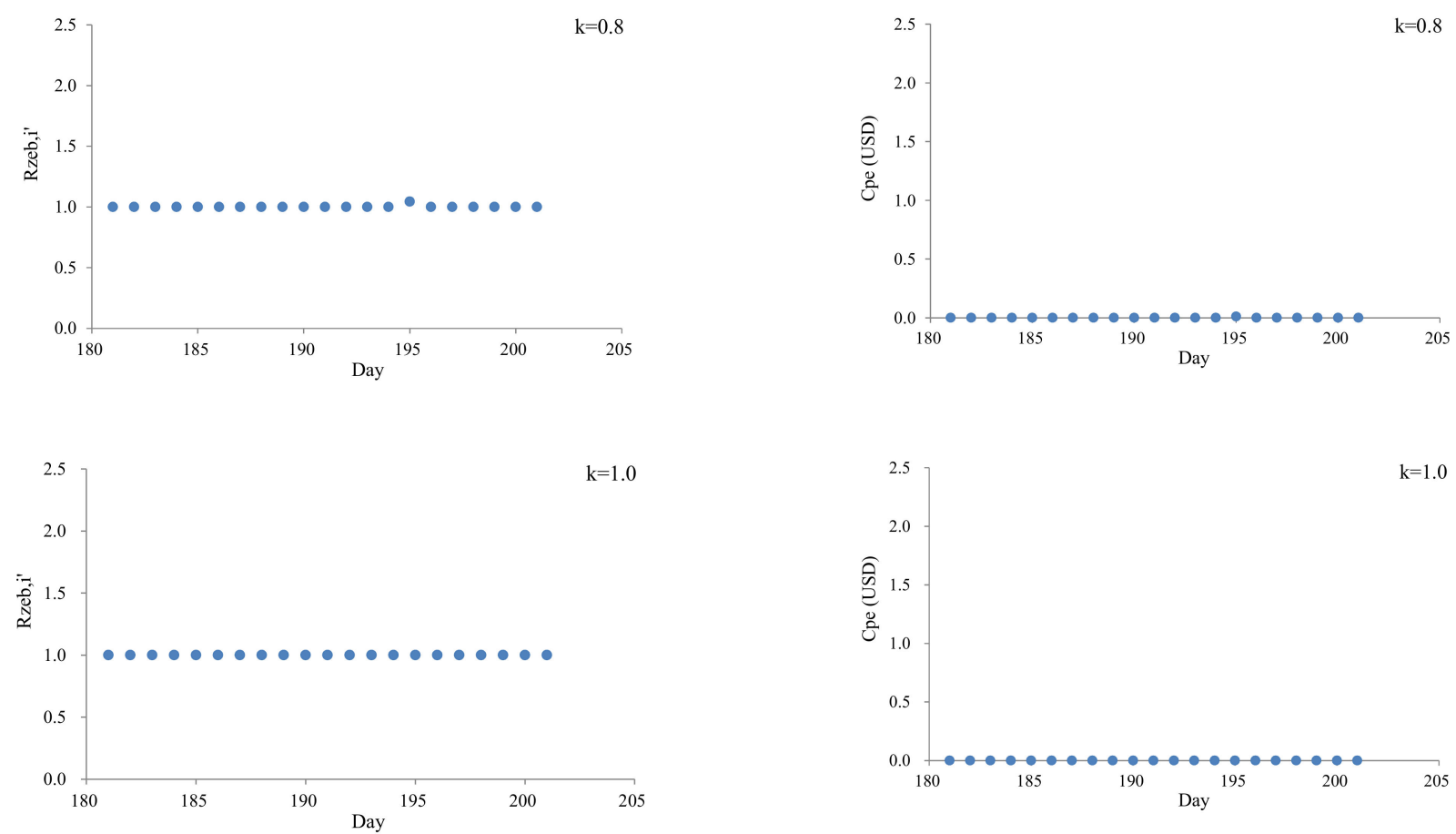

Figure 6. Daily zero energy level and corresponding penalty cost for the building over 21 days.

\subsection{Annual Performance of ZEB Based on RPM}

The performance of the designed ZEB under different degrees of freedom is displayed in Table 2. As can be seen, the total building energy consumption was reduced with the increase of degrees of freedom, from $6984 \mathrm{kWh} / \mathrm{a}$ at $\mathrm{k}$ of 0.0 to $6024 \mathrm{kWh} / \mathrm{a}$ at $\mathrm{k}$ of 1.0 . Since the building users can change their energy consumption patterns, the average daily zero energy level of the building was much closer to 1.0 when $\mathrm{k}$ equaled 1.0. The annual penalty cost was also reduced from $1289.7 \mathrm{USD} / \mathrm{a}$ at $\mathrm{k}$ of 0.0 to $115 \mathrm{USD} / \mathrm{a}$ at $\mathrm{k}$ of 1.0. Four quadratic fit curves, as shown in Figure 7, were derived to describe the relationship between ZEB performance and the degree of freedom, where $0.0 \leq \mathrm{k} \leq 1.0$. Therefore, building users can easily forecast the corresponding building performance versus the degree of freedom by using the fitted curves.

Table 2. ZEB performance under different degrees of freedom.

\begin{tabular}{ccccc}
\hline $\mathbf{k}$ & $\mathbf{E}_{\text {con }}(\mathbf{k W h} / \mathbf{a})$ & $\mathbf{R}_{\text {zeb,ave }}$ & $\boldsymbol{\sigma}$ & $\mathbf{C}_{\mathbf{p e}}$ (USD/a) \\
\hline 0.0 & 6983.9 & 1.51 & 1.20 & 1289.7 \\
0.2 & 6599.2 & 1.34 & 0.91 & 837.8 \\
0.4 & 6217.8 & 1.24 & 0.69 & 523.7 \\
0.6 & 5892.6 & 1.20 & 0.53 & 314.0 \\
0.8 & 5868.2 & 1.16 & 0.40 & 186.9 \\
1.0 & 6024.2 & 1.14 & 0.29 & 115.0 \\
\hline
\end{tabular}



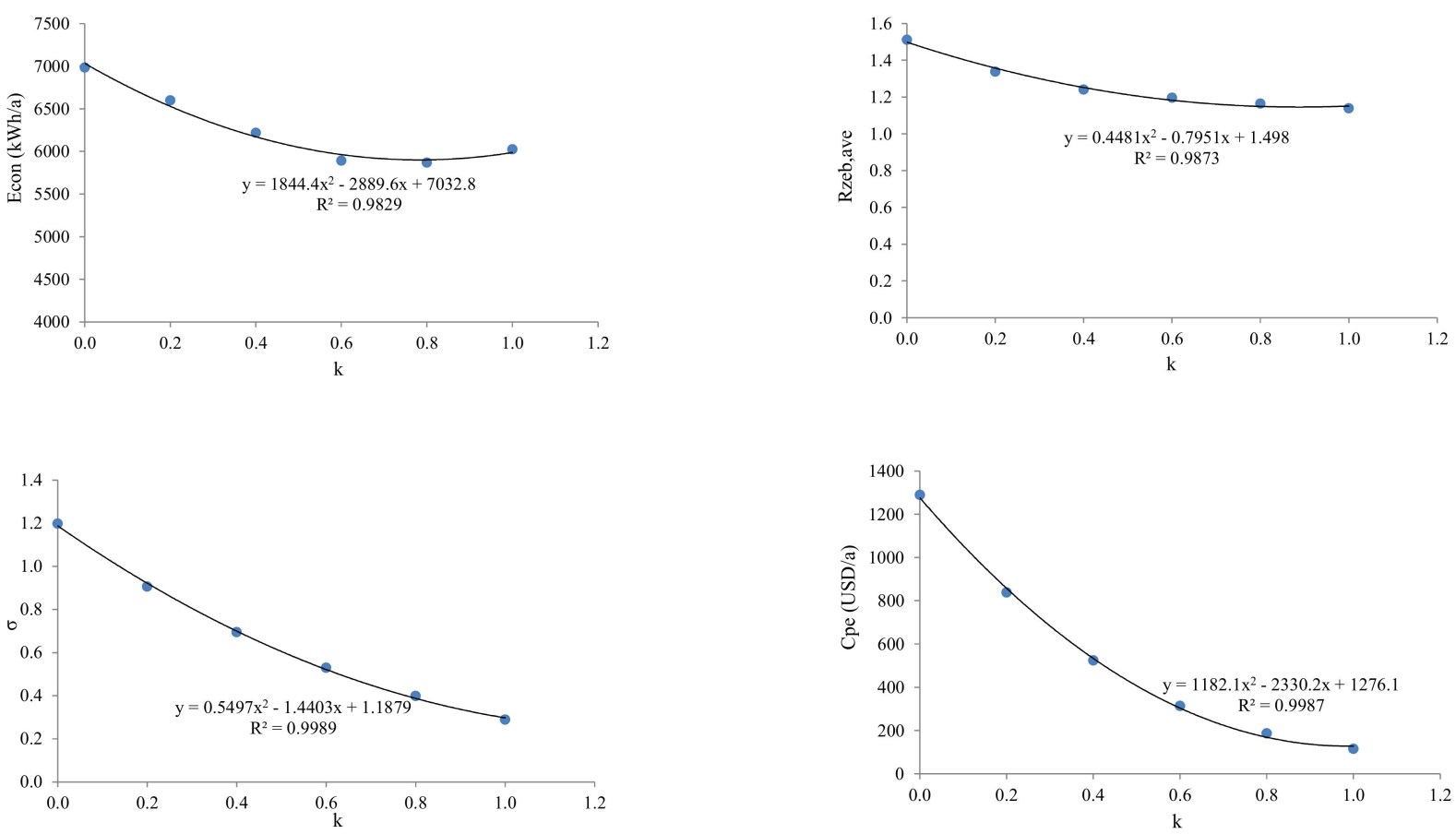

Figure 7. Relationship between average daily zero energy level $\left(\mathrm{R}_{\mathrm{zeb}, \mathrm{ave}}\right)$, stability $(\sigma)$, annual building energy consumption $\left(\mathrm{E}_{\mathrm{con}}\right)$, annual penalty cost $\left(\mathrm{C}_{\mathrm{pe}}\right)$ and the degree of freedom $(\mathrm{k})$.

For annual energy consumption $\left(E_{c o n}\right), E_{c o n}=1844.4 \times \mathrm{k}^{2}-2889.6 \times \mathrm{k}+7032.8, \mathrm{R}^{2}=0.98$; For the average daily zero energy level $\left(R_{z e b, a v e}\right), R_{z e b, a v e}=0.4481 \times \mathrm{k}^{2}-0.7951 \times \mathrm{k}+1.498$, $\mathrm{R}^{2}=0.99$;

For stability $(\sigma), \sigma=0.5497 \times \mathrm{k}^{2}-1.4403 \times \mathrm{k}+1.1879, \mathrm{R}^{2}=1.0$;

For annual penalty cost $\left(C_{\mathrm{pe}}\right), \mathrm{C}_{\mathrm{pe}}=1182.1 \times \mathrm{k}^{2}-2330.2 \times \mathrm{k}+1276.1, \mathrm{R}^{2}=1.0$.

To investigate the impact of building load on the performance of the reward-penalty mechanism, the building energy consumption (BEC) was varied from $0.2 \mathrm{BEC}$ to $1.8 \mathrm{BEC}$ and a Monte Carlo simulation was employed to generate the hourly load. It is noted that the five types of buildings were all designed to be ZEB, which were integrated with PV panels. As shown in Figure 8, the building energy consumption at $0.2 \mathrm{BEC}$ had the smallest variation, from $1387.4 \mathrm{kWh} / \mathrm{a}$ to $1190.8 \mathrm{kWh} / \mathrm{a}$, when the degree of freedom changed from 0.0 to 1.0. By contrast, the building energy consumption at $1.8 \mathrm{BEC}$ had a variation from $12,598 \mathrm{kWh} / \mathrm{a}$ to $10,766 \mathrm{kWh} / \mathrm{a}$ when the degree of freedom changed from 0.0 to 1.0. It is also observed that the average daily zero energy level and the stability of the building nearly kept the same under different BEC levels. For the penalty cost, a building with a larger BEC level deserved to have a higher penalty cost, and it was increased 10 times from $0.2 \mathrm{BEC}$ to $1.8 \mathrm{BEC}$. 

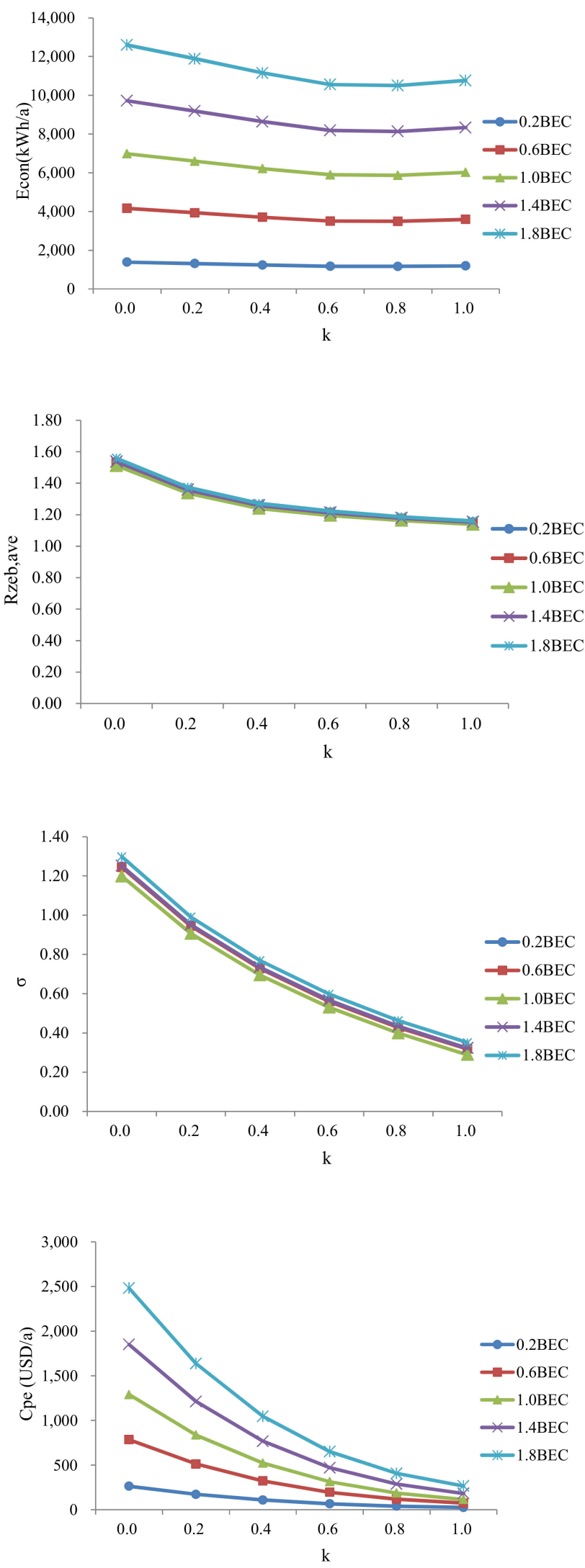

Figure 8. Performance of ZEB under different loads vs the degrees of freedom. 


\subsection{Performance Comparison of ZEB and Non-ZEB Based on RPM}

To further identify the performance difference between designed ZEB and non-ZEB, five designed levels of zero energy balance, i.e., 0.2ZEB, 0.4ZEB, 0.6ZEB, 0.8ZEB, and $1.0 Z E B$, are selected and compared for the building under different degrees of freedom, as shown in Figure 9. In terms of the annual energy consumption, it was the designed value of $6984 \mathrm{kWh} / \mathrm{a}$ for the five levels when $\mathrm{k}$ equaled to 0.0 . With the increase of the $\mathrm{k}$ value, a general reduction was observed for the annual energy consumption in the five levels of ZEB. Meanwhile, the lower level of the building designed (e.g., 0.2ZEB), the smaller energy it will consume at a high $\mathrm{k}$ value. For instance, the annual energy consumption for 0.2ZEB was reduced from $6984 \mathrm{kWh} / \mathrm{a}$ to $1394 \mathrm{kWh} / \mathrm{a}$ when the $\mathrm{k}$ value varied from 0.0 to 1.0, indicating $80 \%$ of energy consumption can be avoided. By contrast, it was reduced from $6984 \mathrm{kWh} / \mathrm{a}$ to $6024 \mathrm{kWh} / \mathrm{a}$ for 1.0ZEB when the $\mathrm{k}$ value varied from 0.0 to 1.0, indicating $13.7 \%$ of energy consumption could be avoided. In terms of the average daily zero energy level of the building, it increased from 0.3 to 1.0 for $0.2 \mathrm{ZEB}$, from 0.6 to 1.0 for $0.4 \mathrm{ZEB}$, and from 0.91 to 1.01 for $0.6 \mathrm{ZEB}$ when $\mathrm{k}$ value varies from 0.0 to 1.0. By contrast, the average daily zero energy level of the building was reduced from 1.21 to 1.06 for $0.8 Z \mathrm{ZEB}$, and from 1.51 to 1.14 for 1.0ZEB when $\mathrm{k}$ value varies from 0.0 to 1.0. Thus, a higher $\mathrm{k}$ value enables the average daily zero energy level around 1.0 for the building.
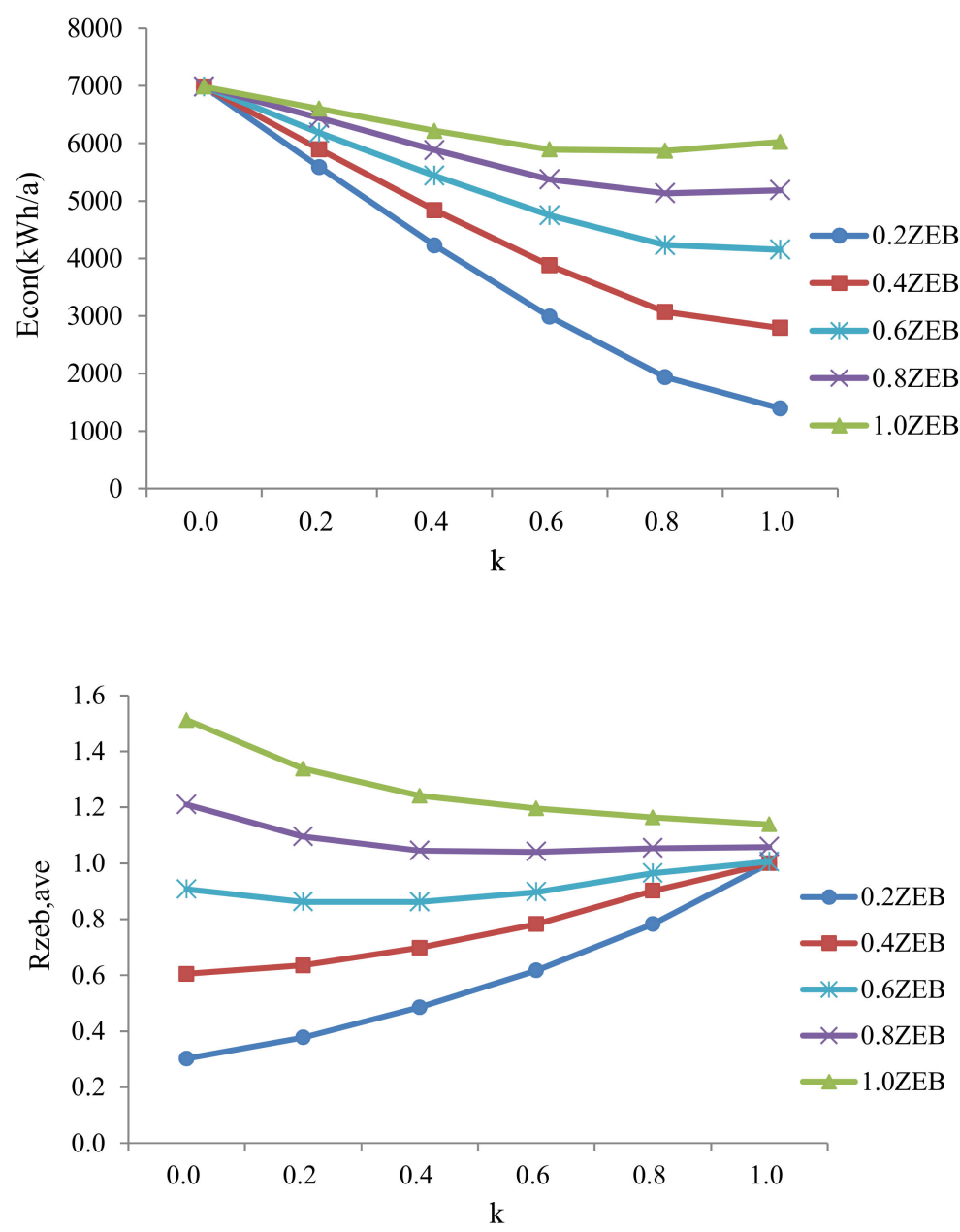

Figure 9. Cont. 

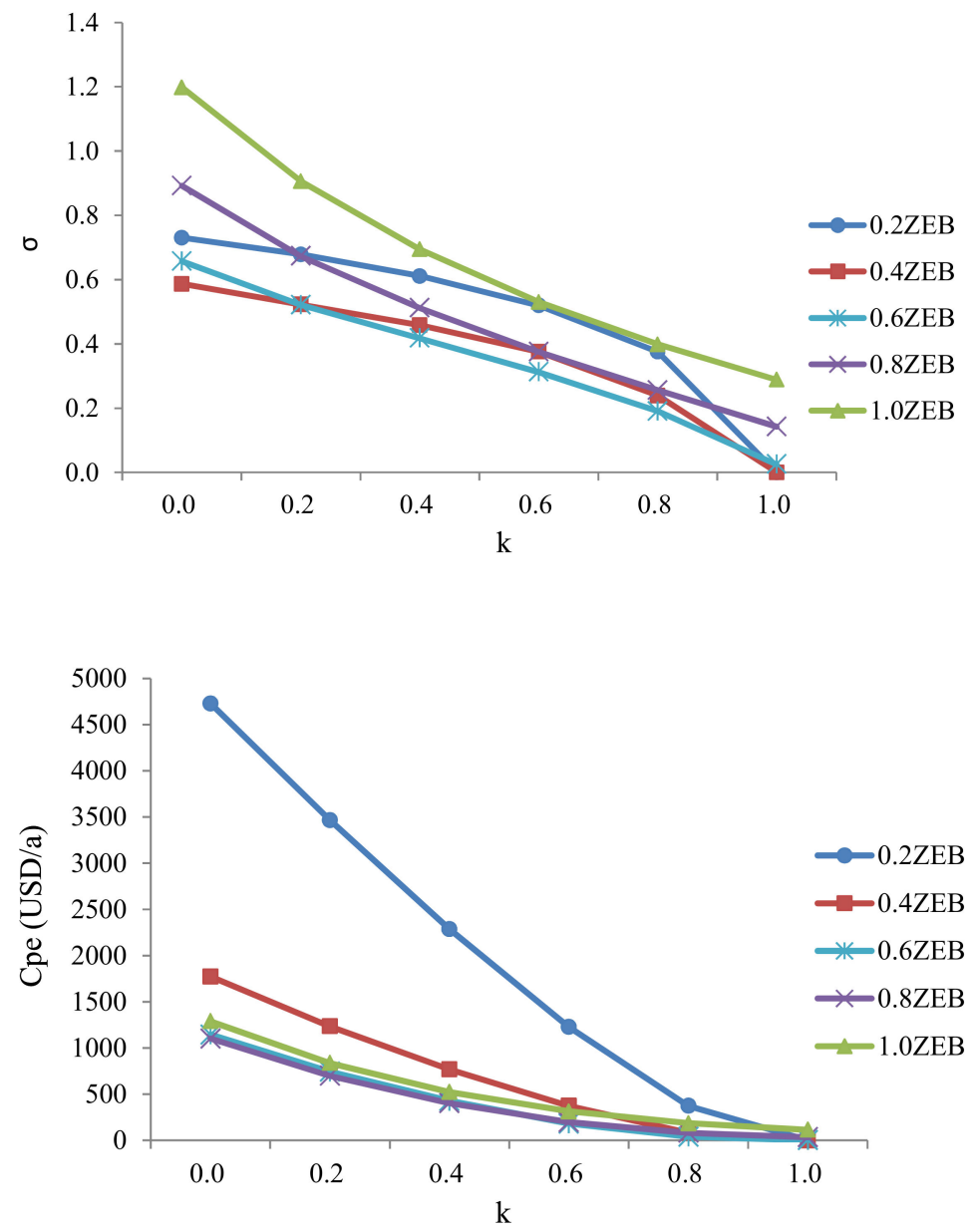

Figure 9. Performance of NZEB and non-NZEB VS the degrees of freedom.

In terms of stability, a general reduction was observed in the five designed levels of ZEB with the increase of the $\mathrm{k}$ value. When the $\mathrm{k}$ value equaled 1.0 for $0.2 \mathrm{ZEB}$ and $0.4 Z E B$, the stability is 0.0 , indicating a good match between building energy consumption and energy generation. For 1.0ZEB, the stability was reduced from 1.2 to 0.29 when the $\mathrm{k}$ value varied from 0.0 to 1.0. Thus, a higher $\mathrm{k}$ value enables a good performance of the building in both designed ZEB and non-ZEB. In terms of penalty cost, the increase of the $\mathrm{k}$ value can greatly reduce the penalty cost, which can be observed from $0.2 \mathrm{ZEB}$, where it is $4727.6 \mathrm{USD} / \mathrm{a}$ at a $\mathrm{k}$ value of 0.0 , and it is reduced to $0.0 \mathrm{USD} / \mathrm{a}$ at a $\mathrm{k}$ value of 1.0 . In $0.2 \mathrm{ZEB}, 0.4 \mathrm{ZEB}$ and $0.6 \mathrm{ZEB}$, the penalty cost is nearly $0.0 \mathrm{USD} / \mathrm{a}$ when $\mathrm{k}$ value reaches 1.0. In addition, the penalty cost in $0.6 \mathrm{ZEB}, 0.8 \mathrm{ZEB}$, and 1.0ZEB has a similar trend starting from around $1200 \mathrm{USD} / \mathrm{a}$ at a $\mathrm{k}$ value of 0.0 , and it is reduced to $1.4 \mathrm{USD} / \mathrm{a}, 34.7 \mathrm{USD} / \mathrm{a}$, and $115 \mathrm{USD} / \mathrm{a}$ at a $\mathrm{k}$ value of 1.0 , respectively.

\subsection{Uncertainty Analysis}

The degree of freedom on the building load is determined by the building users, which is actually an uncertain parameter during the operation phase. In addition, solar radiation is an important factor that determines the generated energy, which is also an uncertain parameter. The Monte Carlo method is employed to generate 100 samples considering uncertainties from the degree of freedom and solar radiation.

In case 1, a random probability between 0.0 and 0.5 is assumed as the degree of freedom, and solar radiation is varied with a ratio between 0.8 and 1.2. The distribution of ZEB performance (i.e., annual building energy consumption $\left(\mathrm{E}_{\mathrm{con}}\right)$, average daily zero energy level $\left(R_{z e b, a v e}\right)$, stability $(\sigma)$, annual penalty $\left.\operatorname{cost}\left(C_{p e}\right)\right)$ is displayed in Figure 10. It 
was found that the annual building energy consumption and average daily zero energy level of the building were expected to vary between $6346.8 \mathrm{kWh} / \mathrm{a}$ and $6683.1 \mathrm{kWh} / \mathrm{a}$, between 1.29 and 1.36, respectively. For the annual building energy consumption, the cumulative probability was $5 \%$ and $95 \%$ at the $6391 \mathrm{kWh} / \mathrm{a}$ and $6591 \mathrm{kWh} / \mathrm{a}$, respectively, and it was $49.0 \%$ at the mean energy consumption $(6504 \mathrm{kWh} / \mathrm{a})$. For the average daily zero energy level of the building, the cumulative probability was 5 and $95 \%$ at 1.30 and 1.35 , respectively, and it was $61.0 \%$ at the mean average daily zero energy level (1.33). Meanwhile, the stability and the annual penalty cost were expected to vary between 0.82 and 0.96 , between 713 USD/a and 893 USD/a, respectively. For stability, the cumulative probability is 5 and $95 \%$ at 0.86 and 0.93 , respectively, and it was $49.0 \%$ at the mean stability (0.90). For the annual penalty cost, the cumulative probability was 5 and $95 \%$ at the $760 \mathrm{USD} / \mathrm{a}$ and $859 \mathrm{USD} / \mathrm{a}$, respectively, and it was $50.0 \%$ at the mean annual penalty cost (812 USD/a), as shown in Table 3.
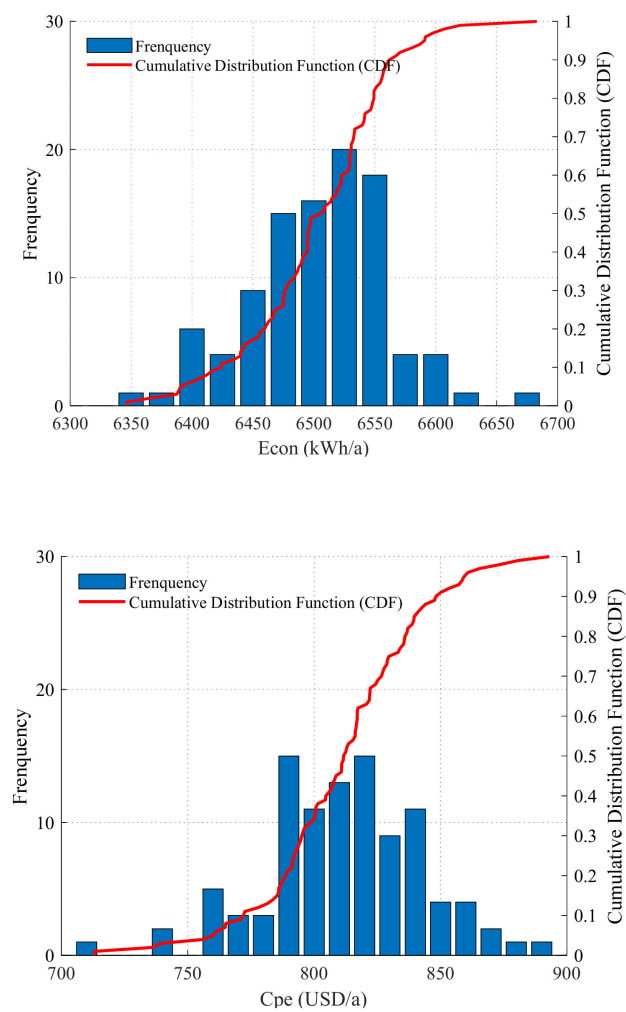
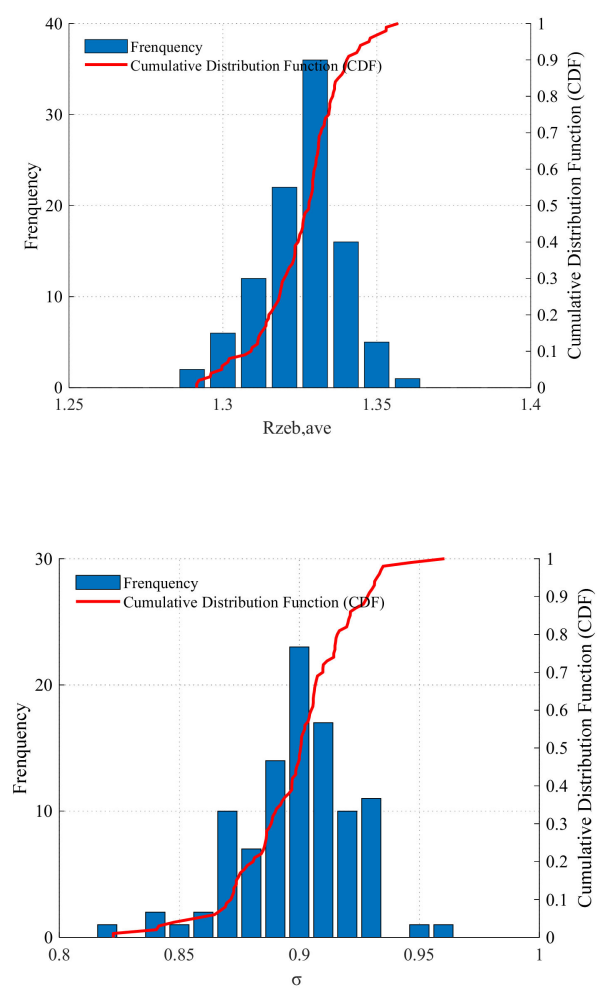

Figure 10. Distribution of building performance under the degree of freedom between 0.0 and 0.5.

Table 3. Uncertainties of building performance ( $\mathrm{k}$ between 0.0 and 0.5 , samples $=100$ years).

\begin{tabular}{cccc}
\hline Performance & Mean & Lower 5th Confidence Level & Upper 95th Confidence Level \\
\hline $\mathrm{E}_{\mathrm{con}}(\mathrm{kWh} / \mathrm{a})$ & 6504 & 6391 & 6591 \\
$\mathrm{R}_{\mathrm{zeb}, \text { ave }}$ & 1.33 & 1.30 & 1.35 \\
$\sigma$ & 0.90 & 0.86 & 0.93 \\
$\mathrm{C}_{\mathrm{pe}}(\mathrm{USD} / \mathrm{a})$ & 812 & 760 & 859 \\
\hline
\end{tabular}

In case 2, a random probability between 0.5 and 1.0 was assumed as the degree of freedom, and solar radiation was the same as it in case 1. The distribution of ZEB performance is displayed in Figure 11. It was found that the annual building energy consumption and average daily zero energy level of the building were expected to vary between $5970 \mathrm{kWh} / \mathrm{a}$ and $6439 \mathrm{kWh} / \mathrm{a}$, between 1.21 and 1.30, respectively. For the annual building energy consumption, the cumulative probability was 5 and $95 \%$ at $6032 \mathrm{kWh} / \mathrm{a}$ 
and $6340 \mathrm{kWh} / \mathrm{a}$, respectively, and it was $58.0 \%$ at the mean annual building energy consumption $(6185 \mathrm{kWh} / \mathrm{a})$. For the average daily zero energy level of the building, the cumulative probability was 5 and $95 \%$ at 1.22 and 1.28 , respectively, and it was $48.0 \%$ at the mean average daily zero energy level (1.25). Meanwhile, the stability and the annual penalty cost were expected to vary between 0.63 and 0.80 , between $433 \mathrm{USD} / \mathrm{a}$ and 615 USD/a, respectively. For stability, the cumulative probability was 5 and $95 \%$ at 0.67 and 0.75 , respectively, and it was $46.0 \%$ at the mean stability $(0.71)$. For the annual penalty cost, the cumulative probability was 5 and $95 \%$ at the 481 USD/a and 585 USD/a, respectively, and it was $51.0 \%$ at the mean annual penalty cost (528 USD/a), as shown in Table 4.
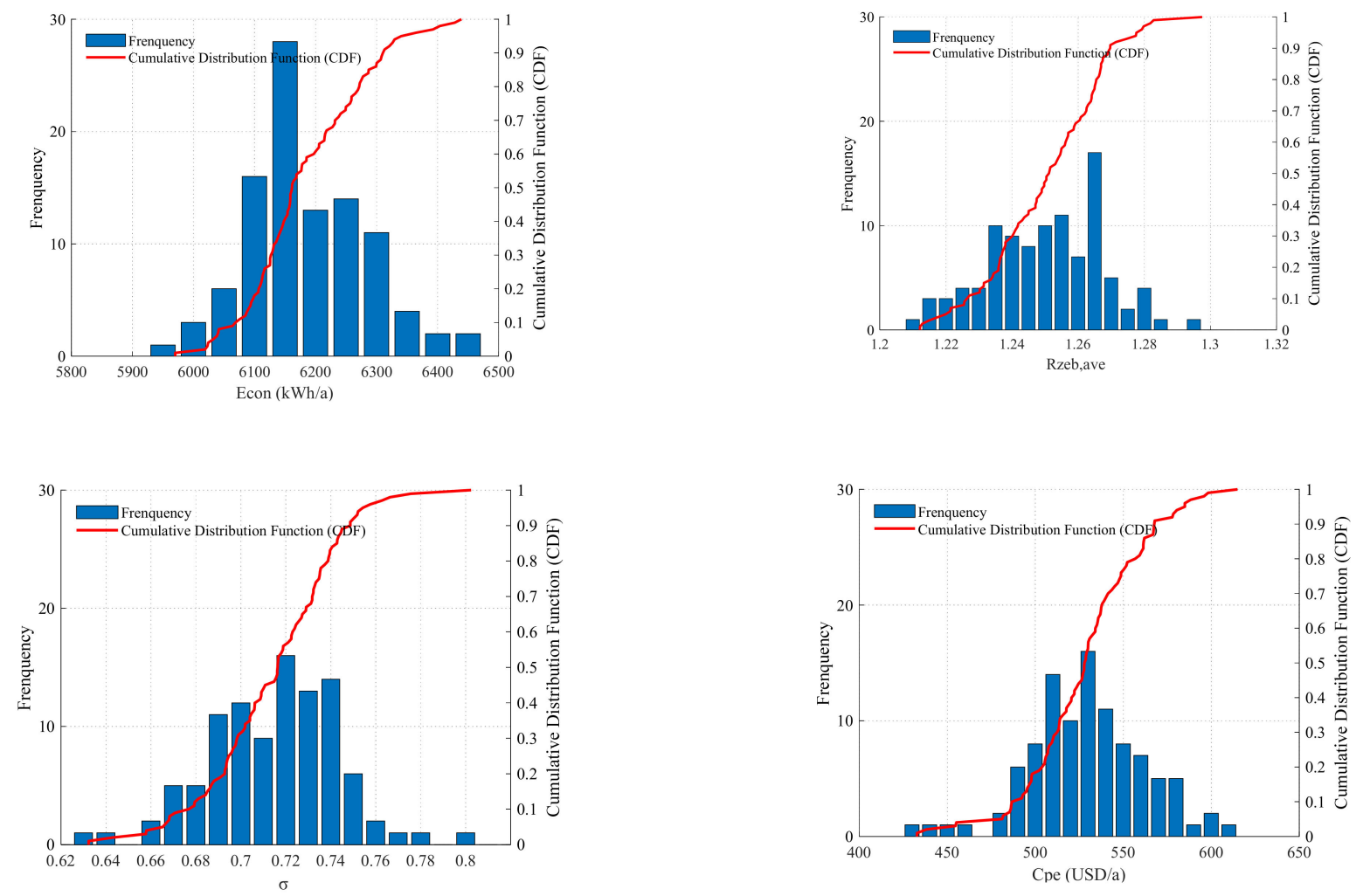

Figure 11. Distribution of Building performance under the degree of freedom between 0.5 and 1.0.

Table 4. Uncertainties of building performance ( $\mathrm{k}$ between 0.5 and 1.0, samples $=100$ years).

\begin{tabular}{cccc}
\hline Performance & Mean & Lower 5th Confidence Level & Upper 95th Confidence Level \\
\hline $\mathrm{E}_{\mathrm{con}}(\mathrm{kWh} / \mathrm{a})$ & 6185 & 6032 & 6340 \\
$\mathrm{R}_{\mathrm{zeb}, \text { ave }}$ & 1.25 & 1.22 & 1.28 \\
$\sigma$ & 0.71 & 0.67 & 0.75 \\
$\mathrm{C}_{\mathrm{pe}}(\mathrm{USD} / \mathrm{a})$ & 528 & 481 & 585 \\
\hline
\end{tabular}

\section{Conclusions and Policy Implication}

In this study, a daily reward-penalty function is proposed for net-zero energy building (NZEB/ZEB) by considering the price of power from the grid, building energy consumption, and power fluctuation. Based on the proposed daily reward-penalty function, building users can adjust the pattern of daily building load to achieve high performance of ZEB. To evaluate and compare the effectiveness of the proposed reward-penalty function under different flexibility of building load (i.e., the degree of freedom on the building load), a case study is conducted for a single-family house located in Shanghai city, China. Several conclusions are obtained as follows: 
(1) The distribution of daily zero energy levels for the building under different degrees of freedom indicates that a higher value of $\mathrm{k}$ is preferred since building users can adjust its energy consumption profile to better match its energy generation. Meanwhile, a building with a $\mathrm{k}$ value of 1.0 is observed to have better stability and lower penalty cost. Therefore, the daily zero energy level and the degree of freedom are two important factors to determine the value of penalty cost.

(2) Four quadratic fit curves are derived to describe the relationship between building performance (i.e., annual energy consumption, the average daily zero energy level, stability, and annual penalty cost) and the degree of freedom. In addition, the impact of building load on the performance of the reward-penalty mechanism is identified by varying the building energy consumption (BEC) from 0.2 BEC to $1.8 \mathrm{BEC}$. It is also observed that the average daily zero energy level and the stability nearly keep the same under different BEC levels.

(3) To compare the performance difference between ZEB and non-ZEB under different degrees of the freedom, five designed levels of ZEB (i.e., 0.2ZEB, 0.4ZEB, 0.6ZEB, $0.8 Z \mathrm{ZB}$, and 1.0ZEB) are selected. A higher k-value enables lower annual energy consumption, lower penalty cost, and better stability in the five levels of ZEB. In addition, a higher $\mathrm{k}$ value enables the average daily zero energy level of the building around 1.0 .

(4) Uncertainty analysis is conducted by considering two parameters (i.e., the degree of the freedom and solar radiation). In case 1, a random probability between 0.0 and 0.5 is assumed as the degree of freedom. The mean building energy consumption, the average daily zero energy level, the stability, and the annual penalty cost are $6504 \mathrm{kWh} / \mathrm{a}, 1.33,0.90$, and $812 \mathrm{USD} / \mathrm{a}$, respectively. In case 2, a random probability between 0.0 and 1.0 is assumed as the degree of freedom. The mean building energy consumption, the average daily zero energy level, the stability, and the annual penalty cost are $6185 \mathrm{kWh} / \mathrm{a}, 1.25,0.71$, and $528 \mathrm{USD} / \mathrm{a}$, respectively.

Incentive measures can greatly accelerate the development of ZEB in different countries. However, only a few studies have been conducted in terms of incentive policies on the specific building, i.e., ZEB. It is generally accepted that ZEB considers the annual energy balance between building energy consumption and on-site energy generation, thus, it is reasonable to design a type of incentive policy based on annual evaluation. However, as the annual reward-penalty mechanism is designed based on annual energy balance, it is difficult to provide detailed incentive measures for building users with daily energy consumption and generation. Considering this, the proposed daily reward-penalty mechanism has a greater advantage over the annual reward-penalty mechanism, which was designed and investigated by the authors in a previous study. In the daily reward-penalty mechanism, building users can be easily involved in daily building energy matching since they have flexibility in the control of building load. Meanwhile, the building under daily reward-penalty mechanism can provide a much more stable power profile compared to that under the annual reward-penalty mechanism, which is beneficial to the power grid and thus preferred to the power grid utilities. To achieve a low penalty cost, building users should reduce their energy consumption and match its energy consumption with energy generation. It is noted that many parameters (e.g., the investment of renewable energy system, the dynamic electricity price, building energy consumption and local renewable resources, etc.) can affect the type of reward-penalty function, further studies on how to design appropriate reward penalty function will be investigated in future studies.

Author Contributions: Conceptualization, abstract, Sections 1 and 5 were contributed jointly by Y.Z. and Y.L.; Section 2 was authored by C.W. and Z.H.; Section 3 was written by T.L. and Y.L. and Section 4 was contributed by Y.Z. and Z.H. Paper writing coordination was carried out by Y.L. and editing by T.L. All authors have read and agreed to the published version of the manuscript. 
Funding: It is acknowledged that this project received funding from the National Natural Science Foundation of China (Project No. 51608001) and the Youth Talent Program in Anhui University of Technology (Project No. DT18200013) to carry out the research work reported in this paper.

Institutional Review Board Statement: Not applicable.

Informed Consent Statement: Not applicable.

Conflicts of Interest: The authors declare no conflict of interest.

\section{References}

1. Goldthau, A. The Handbook of Global Energy Policy; Wiley-Blackwell: Hoboken, NJ, USA, 2013.

2. Jung, Y.; Heo, Y.; Lee, H. Multi-objective optimization of the multi-story residential building with passive design strategy in South Korea. Build. Environ. 2021, 203, 108061. [CrossRef]

3. Wang, S.; Liu, Y.; Cao, Q.; Li, H.; Yu, Y.; Liu, Y. Applicability of passive design strategies in China promoted under global warming in past half century. Build. Environ. 2021, 195, 107777. [CrossRef]

4. Adua, L.; Zhang, K.X.; Clark, B. Seeking a handle on climate change: Examining the comparative effectiveness of energy efficiency improvement and renewable energy production in the United States. Glob. Environ. Chang. 2021, 70, 102351. [CrossRef]

5. Wang, C.; Gu, J.; Martínez, O.S.; Crespo, R.G. Economic and environmental impacts of energy efficiency over smart cities and regulatory measures using a smart technological solution. Suatain. Energy Technol. Assess. 2021, 47, 101422. [CrossRef]

6. Shaughnessy, E.O.; Heeter, J.; Shah, C.; Koebrich, S. Corporate acceleration of the renewable energy transition and implications for electric grids. Renew. Sustain. Energy Rev. 2021, 146, 111160. [CrossRef]

7. Shahbaz, M.; Topcu, B.A.; Sarıül, S.S.; Vo, X.V. The effect of financial development on renewable energy demand: The case of developing countries. Renew. Energy 2021, 178, 1370-1380. [CrossRef]

8. Alvehag, K.; Awodele, K. Impact of Reward and Penalty Scheme on the Incentives for Distribution System Reliability. IEEE Trans. Power Syst. 2014, 29, 386-394. [CrossRef]

9. Janjic, A.; Velimirovic, L.Z.; Vranic, P. Designing an electricity distribution reward-penalty scheme based on spatial reliability statistics. Util. Policy 2021, 70, 101211. [CrossRef]

10. Moradkhani, A.; Haghifam, M.R.; Abedi, S.M. Risk-based maintenance scheduling in the presence of reward penalty scheme. Electr. Power Syst. Res. 2015, 121, 126-133. [CrossRef]

11. Ghasemi, M.; Dashti, R. Designing a decision model to assess the reward and penalty scheme of electric distribution companies. Energy 2018, 147, 329-336. [CrossRef]

12. Ghorashi, S.M.; Rastegar, M.; Senemmar, S.; Seifi, A.R. Optimal design of reward-penalty demand response programs in smart power grids. Sustain. Cities Soc. 2020, 60, 102150. [CrossRef]

13. Islam, M.M.; Sun, Z.; Dagli, C. Reward/Penalty design in demand response for mitigating overgeneration considering the benefits from both manufacturers and utility company. Procedia Comput. Sci. 2017, 114, 425-432. [CrossRef]

14. Ren21. Renewables 2020 Global Status Report; Technical Report; Ren21: Paris, France, 2020.

15. Hitaj, C.; Löschel, A. The impact of a feed-in tariff on wind power development in Germany. Resour. Energy Econ. 2019, 57, 18-35. [CrossRef]

16. Ye, L.; Rodrigues, J.F.D.; Lin, H. Analysis of feed-in tariff policies for solar photovoltaic in China 2011-2016. Appl. Energy 2017, 203, 496-505. [CrossRef]

17. Schmidt, J.; Lehecka, G.; Gass, V.; Schmid, E. Where the wind blows: Assessing the effect of fixed and premium based feed-in tariffs on the spatial diversification of wind turbines. Energy Econ. 2013, 40, 269-276. [CrossRef]

18. Gornowicz, R.; Castro, R. Optimal design and economic analysis of a PV system operating under Net Metering or Feed-In-Tariff support mechanisms: A case study in Poland. Sustain. Energy Technol. Assess. 2020, 42, 100863. [CrossRef]

19. Pacudan, R. Feed-in tariff vs incentivized self-consumption: Options for residential solar PV policy in Brunei Darussalam. Renew. Energy 2018, 122, 362-374. [CrossRef]

20. Tantisattayakul, T.; Kanchanapiya, P. Financial measures for promoting residential rooftop photovoltaics under a feed-in tariff framework in Thailand. Energy Policy 2017, 109, 260-269. [CrossRef]

21. Marszal, A.J.; Heiselberg, P.; Bourrelle, J.S.; Musall, E.; Voss, K.; Sartori, I.; Napolitanno, A. Zero energy building-a review of definitions and calculation methodologies. Energy Build. 2011, 43, 971-979. [CrossRef]

22. Deng, S.; Wang, R.Z.; Dai, Y.J. How to evaluate performance of net zero energy building-A literature research. Energy 2014, 71, 1-16. [CrossRef]

23. Wu, W.; Skye, H.M.; Domanski, P.A. Selecting HVAC systems to achieve comfortable and cost-effective residential net-zero energy buildings. Appl. Energy 2018, 212, 577-591. [CrossRef] [PubMed]

24. Zhang, S.; Sun, Y.; Cheng, Y.; Huang, P.; Oladokun, M.O.; Lin, Z. Response-surface-model-based system sizing for Nearly/Net zero energy buildings under uncertainty. Appl. Energy 2018, 228, 1020-1031. [CrossRef]

25. Lu, Y.; Wang, S.; Zhao, Y.; Yan, C. Renewable energy system optimization of low / zero energy buildings using single-objective and multi-objective optimization methods. Energy Build. 2015, 89, 61-75. [CrossRef] 
26. Lu, Y.H.; Wang, S.W.; Sun, Y.J.; Yan, C.C. Optimal scheduling of buildings with energy generation and thermal energy storage under dynamic electricity pricing using mixed-integer nonlinear programming. Appl. Energy 2015, 147, 49-58. [CrossRef]

27. Sun, Y.; Huang, G.; Xu, X.; Lai, A.C. Building-group-level performance evaluations of net zero energy buildings with noncollaborative controls. Appl. Energy 2018, 212, 565-576. [CrossRef]

28. Majidi, M.; Nojavan, S.; Esfetanaj, N.N.; Najafi-Ghalelou, A.; Zare, K. A multi-objective model for optimal operation of a battery/PV/fuel cell/grid hybrid energy system using weighted sum technique and fuzzy satisfying approach considering responsible load management. Sol. Energy 2017, 144, 79-89. [CrossRef]

29. Lu, Y.; Zhang, X.; Huang, Z.; Wang, D.; Zhang, Y. Penalty-cost-based design optimization of renewable energy system for net zero energy buildings. Energy Procedia 2018, 147, 7-14. [CrossRef]

30. Lu, Y.; Zhang, X.; Li, J.; Huang, Z.; Wang, C.; Luo, L. Design of a reward-penalty cost for the promotion of net-zero energy buildings. Energy 2019, 180, 36-49. [CrossRef] 